\title{
Rapid Enzymatic Degradation of Growth Hormone-releasing Hormone by Plasma In Vitro and In Vivo to a Biologically Inactive Product Cleaved at the $\mathrm{NH}_{2}$ Terminus
}

\author{
Lawrence A. Frohman, Thomas R. Downs, Timothy C. Williams, Edgar P. Heimer, Yu-Ching E. Pan, and Arthur M. Felix \\ Division of Endocrinology and Metabolism, Department of Internal Medicine, University of Cincinnati College of Medicine, Cincinnati, \\ Ohio 45267; and Departments of Peptide Research and Protein Biochemistry, Roche Research Center, Nutley, New Jersey 07110
}

\begin{abstract}
The effect of plasma on degradation of human growth hormonereleasing hormone (GRH) was examined in vitro and in vivo using high performance liquid chromatography (HPLC), ra-

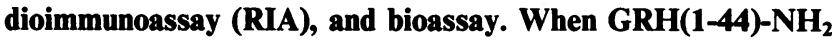
was incubated with human plasma, the $t_{1 / 2}$ of total GRH immunoreactivity was 63 min (RIA). However, HPLC revealed a more rapid disappearance $\left(t_{1 / 2}, 17 \mathrm{~min}\right)$ of $\mathrm{GRH}(1-44)-\mathrm{NH}_{2}$ that was associated with the appearance of a less hydrophobic but relatively stable peptide that was fully immunoreactive. Sequence analysis indicated its structure to be $\mathrm{GRH}(3-44)-\mathrm{NH}_{2}$. Identity was also confirmed by co-elution of purified and synthetic peptides on HPLC. Biologic activity of GRH(3-44)-NH $\mathrm{NHas}_{2}<10^{-3}$ that of GRH(1-44)-NH $\mathbf{N H}_{2}$ After intravenous injection of GRH(144)- $\mathrm{NH}_{2}$ in normal subjects, a plasma immunoreactive peak with HPLC retention comparable to $\mathrm{GRH}(3-44)-\mathrm{NH}_{2}$ was detected within $1 \mathrm{~min}$ and the $t_{1 / 2}$ of $\mathrm{GRH}(1-44)-\mathrm{NH}_{2}$ (HPLC) was 6.8 min. The results provide evidence for GRH inactivation by a plasma dipeptidylaminopeptidase that could limit its effect on the pituitary.
\end{abstract}

\section{Introduction}

Growth hormone $(\mathrm{GH})^{1}$-releasing hormone (GRH) was first identified and sequenced in tumors from which it was ectopically secreted (1-3). Two forms of GRH, GRH(1-40)-OH and GRH(144)- $\mathrm{NH}_{2}$, that have been identified from both tumors and hypothalamus, are identical in structure (4), exhibit indistinguishable biologic activity, and are derived from a single precursor (5).

We have previously described a sensitive and specific radioimmunoassay (RIA) for human GRH(1-40)-OH that was utilized for the determination of metabolic clearance and plasma disappearance rates (6). The kinetics of disappearance of GRH(140)-OH after a single intravenous injection, as measured by RIA, was best explained by a two-pool model with an equilibration

Address correspondence to Dr. Frohman, Division of Endocrinology and Metabolism, ML 547, University of Cincinnati College of Medicine, Cincinnati, OH 45267.

Received for publication 18 April 1986.

1. Abbreviations used in this paper: $\mathrm{ACN}$, acetonitrile; $\mathrm{CRF}$, corticotropinreleasing factor; DAP, dipeptidylaminopeptidase; GH, growth hormone; GRH, growth hormone-releasing hormone; HPLC, high performance liquid chromatography; TFA, trifluoroacetic acid; UV, ultraviolet.

J. Clin. Invest.

(C) The American Society for Clinical Investigation, Inc. $0021-9738 / 86 / 10 / 0906 / 8 \quad \$ 1.00$

Volume 78, October 1986, 906-913 $t_{1 / 2}$ of $8 \mathrm{~min}$ and an elimination $t_{1 / 2}$ of $52 \mathrm{~min}$ that was independent of dose within the $1-10 \mu \mathrm{g} / \mathrm{kg}$ range. Validation of our measurements in this initial study was based on coelution on gel filtration of plasma immunoreactivity and synthetic GRH(140)-OH. The elimination half-time was similar to that observed after discontinuation of a constant infusion of GRH(1-40)-OH and was comparable to results subsequently reported by others (7). The disappearance rate was also similar to that reported for ovine corticotropin-releasing factor (CRF) (8), another releasing hormone of similar size, but was considerably longer than that of other hypothalamic hormones (9-11) and of ACTH (12), a pituitary hormone of comparable size.

With the subsequent report that human CRF exhibited much more rapid clearance than that of ovine CRF from plasma (13), we considered the possibility that our initial results and those of others could be explained by metabolic conversion of GRH within the plasma compartment to another immunoreactive compound(s) with a metabolic clearance rate slower than that of GRH. The present studies were therefore designed to more critically define the molecular form(s) of GRH in plasma after its injection and to search for differences in the clearance of such forms from plasma, if present.

\section{Methods}

\section{Clinical studies}

Subjects studied. Experiments were performed in eight healthy adult male subjects whose ages ranged from 22 to $29 \mathrm{yr}$ and who gave informed written consent. Studies were conducted in the General Clinical Research Center of the University of Cincinnati Hospital, Cincinnati, OH. All subjects had fasted for the preceding $8 \mathrm{~h}$. An indwelling butterfly needle was placed in a vein in each forearm and kept patent with heparinized saline for injection and blood sampling.

Hormone preparation. All studies were performed with GRH(1-44)$\mathrm{NH}_{2}$, provided by Hoffmann-La Roche, Inc., Nutley, NJ.

Protocol. After obtaining a basal sample, subjects were given a rapid intravenous injection of GRH(1-44)- $\mathrm{NH}_{2}, 1 \mu \mathrm{g} / \mathrm{kg}$. Blood samples were collected at $1,3,5,10,15,30,60$, and 120 min, placed into heparinized tubes containing aprotinin (Trasylol; Mobay Chemical Corp., FBA Pharmaceuticals, New York, NY) sufficient to provide a final concentration of 1,000 kallikrein inactivator units $/ \mathrm{ml}$ blood, chilled, and centrifuged. Plasma samples $(2.5-3.5 \mathrm{ml})$ were immediately acidified with $0.25 \mathrm{ml} 1 \mathrm{M} \mathrm{TFA} / \mathrm{ml}$ plasma and extracted on a Sep-pak $\mathrm{C}_{18}$ cartridge (Waters Associates, Millipore Corp., Milford, MA) as previously described $(6,14)$.

In vitro incubations of $G R H(1-44)$ with plasma

Blood was collected from a healthy adult male subject into heparinized tubes and the plasma separated and stored at $-20^{\circ} \mathrm{C}$ until use. For the incubation studies, GRH(1-44)- $\mathrm{NH}_{2}$ (lot \#13004-111; Hoffmann-La Roche, Inc.) or GRH(1-40)-OH (lot \#229-A; Bachem, Torrance, CA) was dissolved in $5 \mathrm{mM}$ acetic acid $(10 \mathrm{mg} / \mathrm{ml})$ and added to plasma at a concentration of $100 \mu \mathrm{g} / \mathrm{ml}$. A $1-\mathrm{ml}$ aliquot of plasma was immediately withdrawn, acidified with $0.25 \mathrm{ml} 1 \mathrm{M}$ trifluoroacetic acid (TFA), and extracted on a Sep-pak $\mathrm{C}_{18}$ cartridge (time 0 ). An additional 1-ml aliquiot of plasma, to which $10 \mu \mathrm{l}$ of $5 \mathrm{mM}$ acetic acid had been added, was also 
extracted at this time and served as a blank. The remaining pool of plasma containing human GRH was incubated at $37^{\circ} \mathrm{C}$ in a shaking water bath at $60 \mathrm{rpm}$. At various time periods from 5 to $120 \mathrm{~min}, 1-\mathrm{ml}$ samples of plasma were withdrawn, extracted, and lyophilized. Samples were resuspended in $0.25 \mathrm{ml} 0.01 \mathrm{M}$ TFA, an aliquot removed for measurement of total GRH immunoreactivity, and the remainder used for chromatography.

\section{High performance liquid chromatography}

High performance liquid chromatography (HPLC) was performed on one of two instruments: model 5020; Varian Associates, Palo Alto, CA, or on a Constametric IIG equipped with a gradient master and Spectromonitor III ultraviolet (UV) variable wavelength detector (LDC/Milton Roy Co., Riviera Beach, FL). The following column, mobile phase, and detection systems were employed.

System A. The column was Vydac $201 \mathrm{TP}, \mathrm{C}_{18}$ (The Separations Group, Hesperia, CA), $250 \times 4.6 \mathrm{~mm}(5 \mu \mathrm{M}$ sorbant); the mobile phase was (A) $0.01 \mathrm{M}$ TFA in $\mathrm{H}_{2} \mathrm{O}$, (B) acetonitrile (ACN); the gradient was $30-35 \% \mathrm{~B}$ in $75 \mathrm{~min}$; the flow was $1 \mathrm{ml} / \mathrm{min}$; and detection was at $210 \mathrm{nM}$.

System B. The column was Vydac 201 TP; the mobile phase was (A) $0.01 \mathrm{M}$ TFA in $\mathrm{H}_{2} \mathrm{O}$, (B) ACN; the gradient was $29 \%$ B isocratic for $50 \mathrm{~min}$ followed by $29-32 \% \mathrm{~B}$ in $45 \mathrm{~min}$; the flow was $1 \mathrm{ml} / \mathrm{min}$; and detection was at $210 \mathrm{nM}$.

System $C$. The column was Spherisorb (ODS-1), $\mathrm{C}_{18}$ (Alltech, Avondale, PA), $250 \times 25 \mathrm{~mm}(5 \mu \mathrm{M}$ sorbant); the mobile phase was (A) $0.5 \%$ TFA in $\mathrm{H}_{2} \mathrm{O}$, (B) $0.025 \%$ TFA in ACN; the gradient was $25-50 \%$ B in $150 \mathrm{~min}$; the flow was $5 \mathrm{ml} / \mathrm{min}$; and detection was at $280 \mathrm{nM}$.

System D. The column was Lichrosorb RP-8, $\mathrm{C}_{18}$ (Alltech Assoc. Inc., Applied Science Labs, Avondale, PA), $250 \times 4 \mathrm{~mm}(5 \mu \mathrm{M}$ sorbant); the mobile phase was (A) $0.1 \mathrm{M}$ perchloric acid (pH 2.5), (B) ACN; the gradient was 35-50\% B in $20 \mathrm{~min}$; the flow was $1 \mathrm{ml} / \mathrm{min}$; and detection was at $206 \mathrm{nM}$.

\section{Amino acid analysis and sequencing}

The isolated metabolite was subjected to structure analysis. Amino acid analysis was performed on an instrument employing postcolumn reaction with fluorescamine (15). Microsequence analysis was carried out on a sequencer (model 470A; Applied Biosystems, Inc., Foster City, CA) (16). PTH-amino acids at each cycle were identified by HPLC (17).

\section{Synthesis of peptides}

GRH(1-44)- $\mathrm{NH}_{2}$ and related peptides were synthesized by the Merrifield solid-phase procedure using sequential additions of the $t$-butyloxycarbonyl (Boc)-protected amino acids to the H-Leu-benzhydrylamine resin (18, 19). After cleavage from the resin with anhydrous liquid hydrogen fluoride, the crude peptide was purified by preparative HPLC with system C. The peptides were shown to be homogeneous by analytical HPLC with system $\mathrm{D}$. After hydrolysis in $6 \mathrm{~N} \mathrm{HCl}$ containing $1 \%$ thioglycolic acid, the peptides gave the expected amino acid composition.

\section{RIA for $G R H$}

Plasma extracts and HPLC fractions were assayed for GRH immunoreactivity by a double-antibody RIA, as previously described $(6,14)$. The $50 \%$ effective dose for the GRH(1-40)-OH standard was $14 \mathrm{fmol} /$ tube with intra- and interassay coefficients of variation of $8.9 \%$ and $12.0 \%$, respectively, for these experiments. $\mathrm{GRH}(1-44)-\mathrm{NH}_{2}$ exhibits $60 \%$ crossreactivity with parallel displacement to the $\mathrm{GRH}(1-40)-\mathrm{OH}$ reference standard in this assay system.

\section{Bioassay for GRH}

Monolayer cultures of dispersed pituitary cells from adult male SpragueDawley rats (Harlan Sprague-Dawley, Inc., Indianapolis, IN) were prepared as previously described $(14,20)$. After a 72 -h culture period, the cells were exposed during a 4-h incubation to synthetic GRH(1-44)- $\mathrm{NH}_{2}$ and/or synthetic GRH(3-44)- $\mathrm{NH}_{2}$ (lot \#1 166-287; Hoffmann-La Roche, Inc.), or to partially purified GRH(3-44)- $\mathrm{NH}_{2}$ from in vitro plasma in- cubations. Rat GH secreted into the medium was measured by a specific RIA (21) and the results expressed in terms of an NIADDK rat GH RP1 reference standard. The intraassay coefficient of variation for the rat GH assay was $3.1 \%$.

\section{Data analyses}

Plasma disappearance curves of human GRH were determined by biexponential analysis using the SAAM 27 curve fitting computer program (6), as adapted to a DEC (Digital Equipment Corp., Maynard, MA) VAX computer (CONSAM). Results are expressed as mean \pm SEM and the significance of differences between group means were determined by the $t$ test. The relative potency of the metabolite in the in vitro bioassay was determined by covariance analysis.

\section{Results}

Incubation of $\mathrm{GRH}(1-44)-\mathrm{NH}_{2}$ with human plasma in vitro The incubation of $100 \mu \mathrm{g} \mathrm{GRH}(1-44)-\mathrm{NH}_{2}$ with human plasma in vitro initially revealed a disappearance $t_{1 / 2}$ of $63 \mathrm{~min}$ based on RIA of total GRH immunoreactivity remaining in the plasma extract (data not shown). However, after HPLC separation of the extracts using system $\mathrm{A}$, a much more rapid disappearance of true GRH(1-44)- $\mathrm{NH}_{2}$ was observed, as seen in Fig. 1. The HPLC absorbance profiles of the plasma extract alone (dotted line) or in the presence of $100 \mu \mathrm{g} \mathrm{GRH}(1-44)-\mathrm{NH}_{2}$, but without incubation (solid line), using HPLC system $A$ are shown in the upper left panel. The profiles of plasma incubated with GRH(144)- $\mathrm{NH}_{2}$ for periods ranging from 5 to $120 \mathrm{~min}$ are shown sequentially from left to right. $\mathrm{GRH}(1-44)-\mathrm{NH}_{2}$ eluted in a position relatively free of endogenous plasma peaks (at $\sim 25 \mathrm{~min}$ ) in this HPLC system and disappeared rapidly from incubated plasma. The decrease in the concentration of GRH(1-44)- $\mathrm{NH}_{2}$ displayed first order kinetics through $60 \mathrm{~min}$ when plotted either as the integrated area under the curve (UV absorbance) or by RIA of GRH(1-44)- $\mathrm{NH}_{2}$ in individual HPLC fractions, as seen in Fig. 2. The disappearance rate half-time for GRH(1-44)-- $\mathrm{NH}_{2}$ in human plasma in vitro was 17 min by both absorbance and by RIA measurement.

Concomitant with the disappearance of GRH(1-44)- $\mathrm{NH}_{2}$ from incubated plasma in vitro was the appearance of a less hydrophobic, immunoreactive metabolite which coeluted with an endogenous plasma protein at $\sim 18 \mathrm{~min}$ (Fig. 1). The concentration of this peptide, quantitated by RIA or by integration of the area under the curve after subtracting the area of the endogenous plasma protein, is also shown in Fig. 2. The quantity of this metabolite exceeded that of human GRH(1-44)-NH $\mathrm{NH}_{2}$ by $\sim 25 \mathrm{~min}$ and remained relatively constant during the remainder of the incubation period.

\section{Identification and characterization of the GRH metabolite}

Amino acid and sequence analysis. The major immunoreactive metabolite peak from the 30-and 60-min incubations was pooled and separated from the coeluting contaminant present in plasma by use of another HPLC system (system B). The amino acid composition of this material revealed the loss of one tyrosine and one alanine residue from the expected composition of GRH(1-44)-NH $\mathrm{NH}_{2}$. These residues represent positions 1 and 2, respectively, of the native peptide. Sequence analysis of the metabolite revealed the $\mathrm{NH}_{2}$-terminal residue to be aspartate, which is normally present in position 3 (Fig. 3).

Chromatography. Additional evidence of the identity of the metabolite as GRH(3-44)- $\mathrm{NH}_{2}$ was provided by co-chromatography of the purified metabolite and synthetic GRH(3-44)-- $\mathrm{NH}_{2}$ 

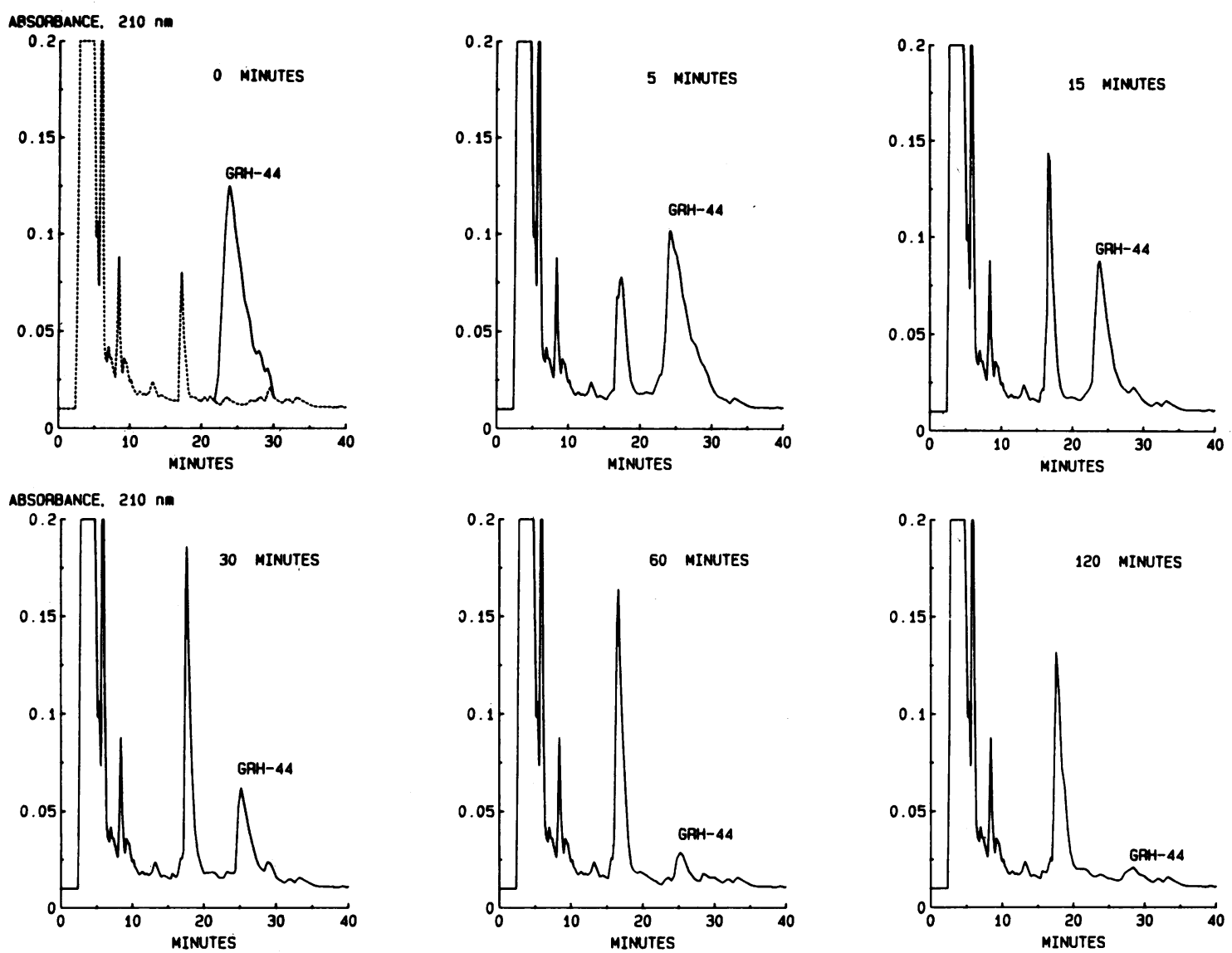

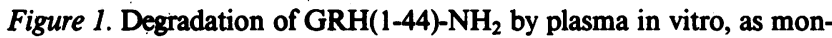
itored by HPLC. GRH, $100 \mu \mathrm{g}$, was incubated with normal human plasma for the time periods indicated, extracted, and subjected to HPLC as described. Shown are the absorbance patterns at $210 \mathrm{~nm}$. The interrupted line in the upper left panel indicates the absorbance pattern of plasma in the absence of GRH. Superimposed as a solid

line is the additional absorbance contributed by GRH. The absorbance patterns at 5 through $120 \mathrm{~min}$ are shown in the other panels. The GRH metabolite peak that eluted at $18 \mathrm{~min}$ and increased with time through $30 \mathrm{~min}$ coeluted with an endogenous plasma peak, evident at $\mathbf{0 ~} \mathrm{min}$ in interrupted lines, using chromatographic system $\mathbf{A}$.

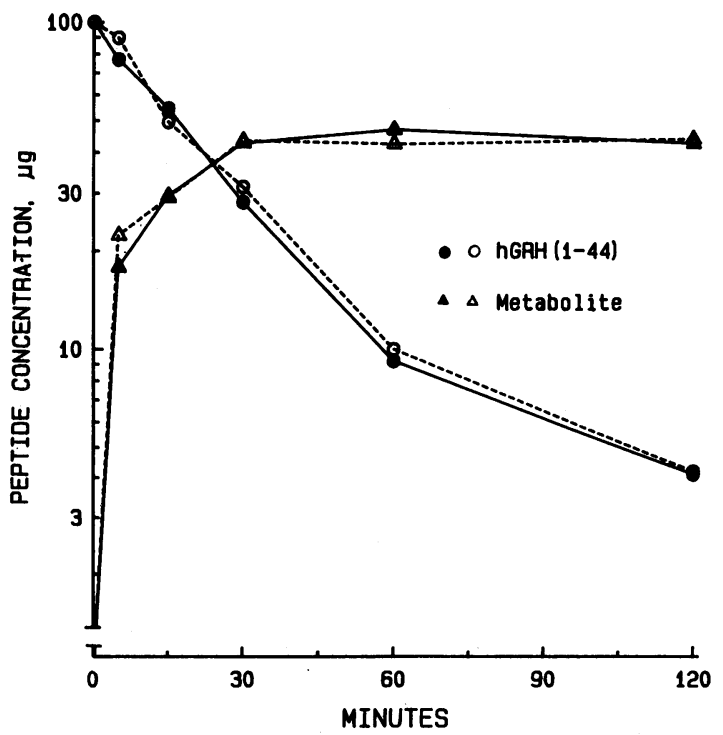

using system C. The elution pattern of $1.2 \mu \mathrm{g}$ synthetic GRH(344)- $\mathrm{NH}_{2}$ is shown at left in Fig. 4. When equal quantities of synthetic GRH(3-44)- $\mathrm{NH}_{2}$ and the metabolite were co-chromatographed (right), only a single peak was observed, indicating an identical retention time for the two peptides.

Radioimmunoassay. Synthetic GRH(3-44)- $\mathrm{NH}_{2}$ exhibited parallel displacement with the GRH(1-40)-OH reference standard and a cross-reactivity (60\%) indistinguishable from that of GRH(1-44)-NH2.

Bioassay. A comparison of the biologic activity of synthetic and plasma generated $\mathrm{GRH}(3-44)-\mathrm{NH}_{2}$ with that of synthetic

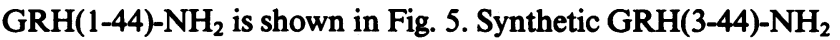
exhibited full agonist activity in the pituitary monolayer culture system and the slope of its dose-response curve was not signif-

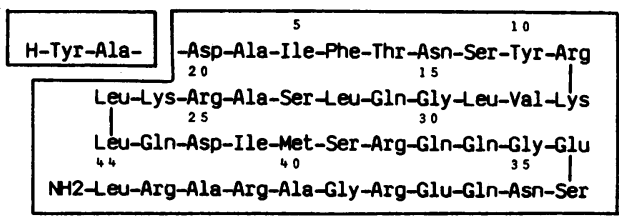

Figure 2. Time course of the disappearance of GRH(1-44)-NH $\mathrm{NH}_{2}$ and appearance of the metabolite during incubation with normal human plasma. Data is derived from integration of the peaks in Fig. 1 as determined by UV absorption (closed symbols) and by RIA (open symbols). All values were corrected for recovery. No quantitative differences were noted between the two measurement parameters.

Figure 3. Amino acid sequence of human GRH(1-44)- $\mathrm{NH}_{2}$ indicating the site of enzymatic cleavage resulting in removal of two amino-terminal residues. 

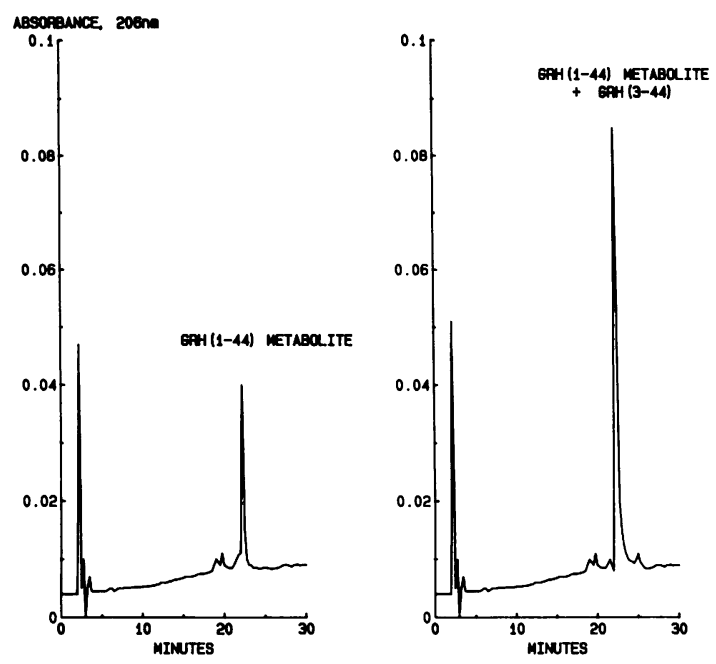

Figure 4. HPLC of $1.2 \mu \mathrm{g}$ of purified GRH(1-44)- $\mathrm{NH}_{2}$ metabolite alone (left) and in combination with $1.2 \mu \mathrm{g}$ of synthetic GRH(3-44)$\mathrm{NH}_{2}$ (right) using system $\mathrm{C}$.

icantly different from that of GRH(1-44)-NH2. The $50 \%$ effective dose of $\mathrm{GRH}(3-44)-\mathrm{NH}_{2}$ was $170 \mathrm{nM}$, as compared with 0.027

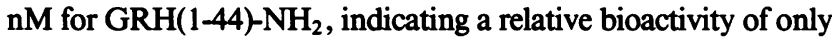
$0.016 \%$. The slope of the dose-response curve and the potency of the plasma-generated $\mathrm{GRH}(3-44)-\mathrm{NH}_{2}$ preparation was indistinguishable from that of the synthetic peptide. In a separate study, the presence of $1.0 \mathrm{nM}$ synthetic $\mathrm{GRH}(3-44)-\mathrm{NH}_{2}$ in combination with 0.01 to $1.0 \mathrm{nM} \mathrm{GRH}(1-44)-\mathrm{NH}_{2}$ did not reveal any evidence of antagonist activity (data not shown).

Incubation of GRH(3-44)-NH $\mathrm{NH}_{2}$ and $\mathrm{GRH}(1-40)-\mathrm{OH}$ with human plasma in vitro

When synthetic GRH(3-44)- $\mathrm{NH}_{2}$ was incubated with human plasma under the identical conditions as described for GRH(1-

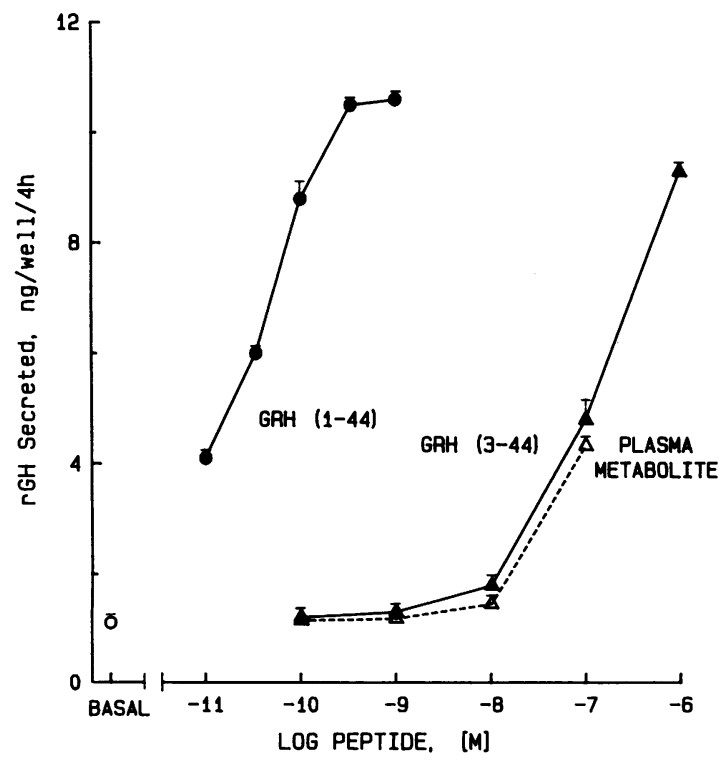

Figure 5. GH-releasing effects of GRH(1-44)- $\mathrm{NH}_{2}$, HPLC-purified GRH metabolite, and synthetic GRH(3-44)- $\mathrm{NH}_{2}$ in rat pituitary cell cultures. Shown are the mean \pm SEM of four replicate incubations. The purified metabolite was added in concentrations based on RIA.
44)- $\mathrm{NH}_{2}$, a decrease in the GRH(3-44)- $\mathrm{NH}_{2} \mathrm{UV}$ absorption peak on HPLC occurred with time, though at a considerably slower rate than observed with $\mathrm{GRH}(1-44)-\mathrm{NH}_{2}$ (Fig. 6). The decrease in GRH(3-44)- $\mathrm{NH}_{2}$ concentration, as determined by UV absorption, exhibited first order kinetics through 120 min with a $t_{1 / 2}$ of $55 \mathrm{~min}$. The disappearance of human GRH(1-40)-OH after incubation with plasma also exhibited an exponential disappearance with a $t_{1 / 2}$ of $24 \mathrm{~min}$. The half-time of GRH(1-44)$\mathrm{NH}_{2}$ in this experiment was $15 \mathrm{~min}$.

\section{Characterization of plasma GRH immunoreactivity by $H P L C$ after injection of $\mathrm{GRH}(1-44)-\mathrm{NH}_{2}$}

The levels of plasma GRH in individual HPLC fractions after the intravenous injection of $1 \mu \mathrm{g} / \mathrm{kg} \mathrm{GRH}(1-44)-\mathrm{NH}_{2}$ were well beneath the concentrations required for UV detection and were measured by RIA. Chromatography data was available at all time periods ( 1 through $30 \mathrm{~min}$ ) for six of the eight studies. Fig. 7 illustrates the pattern of GRH immunoreactivity in a single subject and is representative of the results observed in each of the others. At the earliest time period examined $(1 \mathrm{~min})$ nearly

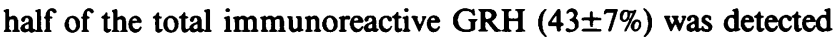
in a peak with a retention time indistinguishable from that of synthetic GRH(3-44)- $\mathrm{NH}_{2}$, with most of the remaining immunoreactivity appearing as $\mathrm{GRH}(1-44)-\mathrm{NH}_{2}$. While both peaks decreased with time, that of $\mathrm{GRH}(1-44)-\mathrm{NH}_{2}$ disappeared much more rapidly and was barely detectable by $30 \mathrm{~min}$. A small amount of immunoreactive GRH was also present at and just beyond the column void volume.

\section{Plasma disappearance rates of GRH immunoreactivity and $\mathrm{GRH}(1-44)-\mathrm{NH}_{2}$}

A comparison of the plasma disappearance curves of GRH(144)- $\mathrm{NH}_{2}$ and of total immunoreactive GRH after intravenous

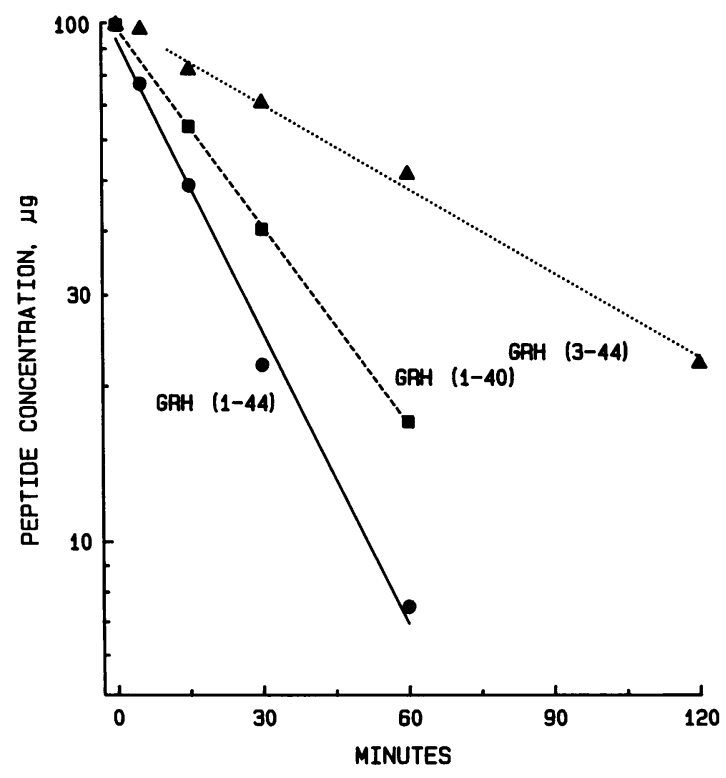

Figure 6. Comparison of the disappearance of $100 \mu \mathrm{g}$ each of GRH(144)- $\mathrm{NH}_{2}, \mathrm{GRH}(1-40)-\mathrm{OH}$, and $\mathrm{GRH}(3-44)-\mathrm{NH}_{2}$ during incubation with plasma in vitro. The values for each peptide were determined by integration of the HPLC-purified UV absorption peak. Chromatography conditions were as in system $A$. 

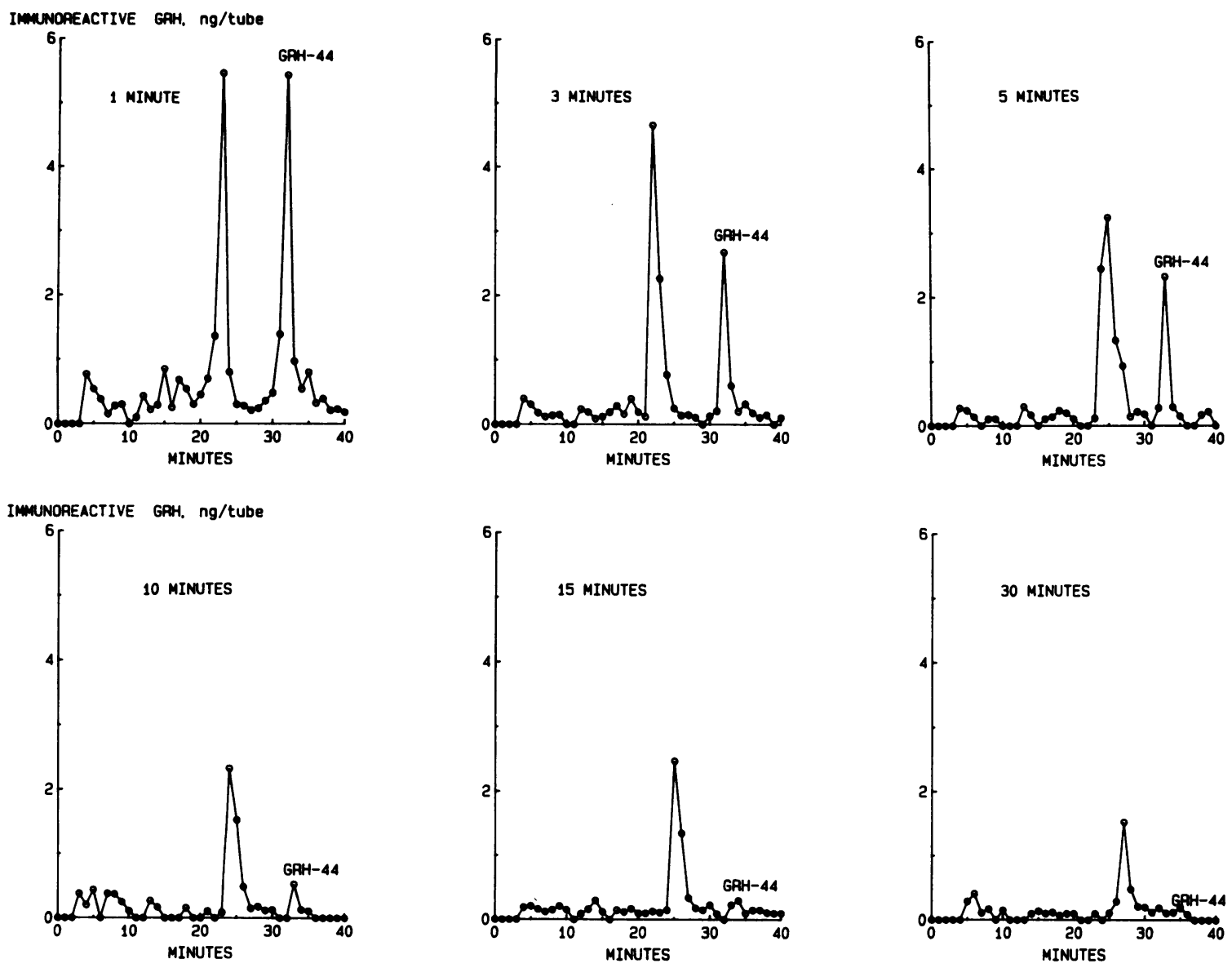

Figure 7. HPLC profiles of plasma GRH immunoreactivity at various time periods after the intravenous injection of GRH(1-44)- $\mathrm{NH}_{2}, 1 \mu \mathrm{g} /$ kg. Blood samples were centrifuged and plasma extracted immediately after withdrawal. The conditions of chromatography were as in system A except that another Vydac column was used. Shown are the results

of a single subject. Similar results were observed in five other subjects. In most subjects, no detectable immunoreactive peak at the elution position of GRH(1-44)-NH $\mathrm{NH}_{2}$ was seen beyond $15 \mathrm{~min}$. The earlier eluting peak of immunoreactivity coincided with that of synthetic GRH(3-44)-NH $\mathrm{NH}_{2}$.

injection of GRH(1-44)-NH $\mathrm{NH}_{2}$ is shown in Fig. 8. The true GRH(144)- $\mathrm{NH}_{2}$ concentration was determined by integration of the GRH(1-44)- $\mathrm{NH}_{2}$ peak (as determined by RIA) on the HPLC analysis of plasma from each subject at each time point. The distribution $\left(t_{1 / 2} \alpha\right)$ and elimination $\left(t_{1 / 2} \beta\right)$ phase half-times for total GRH immunoreactivity were $2.7 \pm 0.6$ and $16.0 \pm 1.2 \mathrm{~min}$, and for $\mathrm{GRH}(1-44)-\mathrm{NH}_{2}$ were $1.0 \pm 0.2$ and $6.8 \pm 1.2 \mathrm{~min}$. $(P<0.05$ and $P<0.001)$, respectively. Shown for comparison in the interrupted line is the disappearance curve for the combined series of injections of $\mathrm{GRH}(1-40)-\mathrm{OH}$, as previously reported (6).

\section{Discussion}

The results of the present studies clearly indicate that exposure of $\mathrm{GRH}(1-44)-\mathrm{NH}_{2}$ to plasma results in rapid degradation to a peptide that is modified at the $\mathbf{N H}_{2}$ terminus and exhibits considerable differences in biologic and pharmacokinetic properties. These studies were prompted by the apparent inconsistency of our previous metabolic clearance results with the findings reported for other hypothalamic hormones. Although we raised the possibility of in vivo GRH metabolism during our continuous infusion studies (6), the constant infusion of fresh GRH(1-40)-
$\mathrm{OH}$ into plasma, together with the limited resolving capability of gel filtration chromatography, resulted in our inability to distinguish between the native hormone and the metabolite degraded at the $\mathrm{NH}_{2}$ terminus. The improved resolution of HPLC clearly indicated, however, that GRH was being rapidly metabolized both in vivo and in vitro.

We initially performed in vitro studies because the concentrations of GRH that could be used were readily detectable by UV absorption, thereby precluding the need for either radioiodinated hormone, which might exhibit different degradation characteristics, as has been shown for insulin (22), or reliance on RIA for quantification, since immunoreactivity of the possible metabolites could vary considerably. The results demonstrated that the disappearance of GRH(1-44)- $\mathrm{NH}_{2}$ in vitro was considerably more rapid than that of either GRH(1-40)-OH (6) or total GRH(1-44)- $\mathrm{NH}_{2}$ immunoreactivity in vivo. Based on the structure of GRH, we initially suspected that the cleavage would occur at positions 11-12 or 20-21, the sites of dibasic residues susceptible to the action of trypsin-like enzymes. The retention of full immunoreactivity by the metabolite (on the basis of UV absorption) suggested that there was relatively limited size change in the number of residues and, therefore, that the site of degradation was near the $\mathrm{NH}_{2}$ terminus, since the antibody rec- 


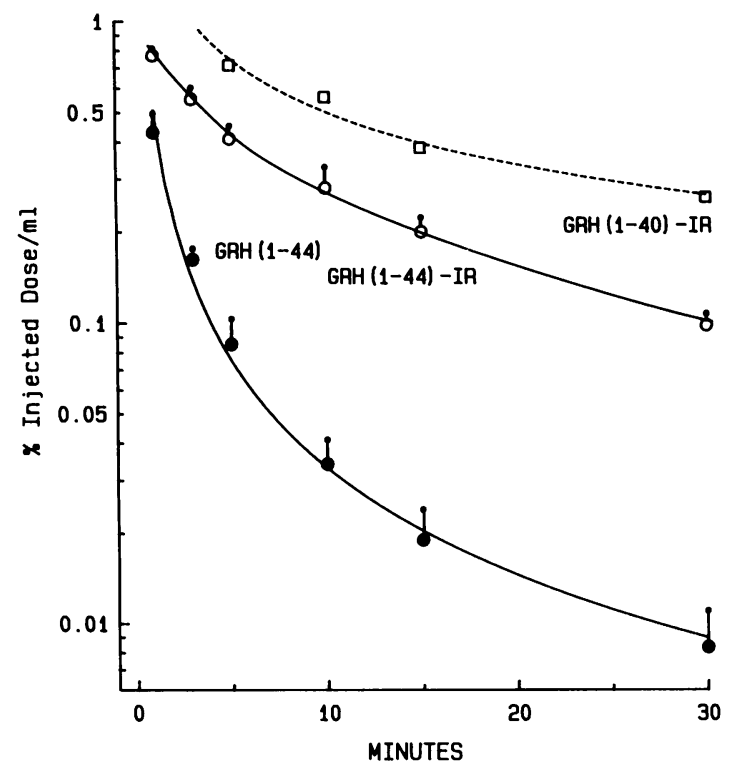

Figure 8. Disappearance curves (mean \pm SEM) of HPLC-purified GRH(1-44)-- $\mathrm{NH}_{2}(n=6)$ and of total GRH immunoreactivity in extracted plasma $(n=8)$ after the intravenous injection of GRH(1-44)$\mathrm{NH}_{2}, 1 \mu \mathrm{g} / \mathrm{kg}$. Shown for comparison in the interrupted line is the disappearance of total GRH immunoreactivity after intravenous injection of GRH(1-40)-OH, as previously reported (6).

ognition sites were on the $\mathrm{COOH}$-terminal portion of the molecule (14).

Amino acid composition and sequence analysis of the metabolite revealed that, indeed, the molecule was reduced in size by removal of only two residues at the amino terminus. Sequencing was repeated on several different purified preparations and gave identical results. Confirmation of the sequence was demonstrated by coelution of synthetic and enzymatically converted GRH(3-44)- $\mathrm{NH}_{2}$ on HPLC and by indistinguishable bioactivity and immunoreactivity.

The bioactivity of GRH(3-44)- $\mathrm{NH}_{2}$ in a cultured pituitary cell system was reduced by a factor of $>5,000$, as would have been expected on the basis of previous studies that demonstrated the critical importance of the $\mathrm{NH}_{2}$ terminal region of the molecule (23-25). Our results revealed that GRH(3-44)- $\mathrm{NH}_{2}$ is a full agonist and does not inhibit the GH-releasing effects of GRH(1-44)-NH2 $\mathrm{NH}_{2}$ Thus, the initial biodegradation of GRH results in virtually complete inactivation of the hormone, though without generation of antagonist properties.

The results of the plasma incubation studies raised the possibility of an in vitro artifact that might not be present in vivo. This explanation was excluded by our in vivo results. Since the quantity of GRH that could be injected into humans resulted in plasma GRH levels considerably beneath those required for UV detection, it was necessary to use RIA for monitoring the GRH profile on HPLC. However, the demonstration that GRH(3-44)- $\mathrm{NH}_{2}$ exhibited full cross-reactivity with GRH(1-44)$\mathrm{NH}_{2}$ in our RIA provided the necessary validation for the quantitative use of this technique. Although the levels of GRH immunoreactivity in plasma at various times after injection of GRH were insufficient for additional characterization, the retention times observed are completely consistent with an extremely rapid conversion (evident within $1 \mathrm{~min}$ ) of $\mathrm{GRH}(1-44)-\mathrm{NH}_{2}$ to GRH(3-44)-NH $\mathrm{NH}_{2}$.
The half-time of total GRH immunoreactivity in vivo in the present study (in which GRH(1-44)- $\mathrm{NH}_{2}$ was injected) was considerably shorter than that after injection of GRH(1-40)-OH (6). Although this may, in part, be attributed to use of a different GRH antibody in the present study, the in vitro experiments also indicated that GRH(1-40)-OH is more resistant to degradation by plasma peptidases than is GRH(1-44)-NH $\mathrm{NH}_{2}$. Since the primary cleavage of GRH(1-40)-OH is to GRH(3-40)-OH (data not shown), a question must be raised as to why a four-amino acid difference at the carboxyl terminus of the hormone should affect an enzymatic reaction occurring at the amino terminus. Additional studies of the conformational structures of the two GRH forms may be required to provide an answer. The significance of this finding in relation to the relative biologic activity of the two hormonal forms after in vivo injection will also require further study, though a comparison of the GH-releasing activity of intravenously injected GRH(1-44)- $\mathrm{NH}_{2}$ and GRH(1-40)-OH in normal human subjects revealed virtually identical potency (26).

The enzyme(s) responsible for this initial step of GRH degradation remains to be identified, as does its source. However, preliminary data (not shown) suggests that GRH is cleaved by removal of a dipeptide rather than by two sequential removals of a single amino acid. The nature of the dipeptidylaminopeptidase (DAP) and its relation to other characterized enzymes of this type (27) remain to be determined. However, on the basis of the known properties of the individual enzymes comprising this subgroup of exopeptide hydrolases, we find that the enzymatic activity is most consistent with that of DAP-IV. In preliminary experiments we have found similar GRH(1-44)- $\mathrm{NH}_{2}$ degrading activity in rat plasma, though full characterization of the metabolite has not been performed. Inspection of data contained in a recent report describing the incubation of ${ }^{125} \mathrm{I}-\mathrm{GRH}(1-$ 40)-OH with rat plasma also reveals a degenerative pattern on gel filtration that is consistent with the generation of an $\mathbf{N H}_{2}$ terminal dipeptide (28).

The present results, at first inspection, appear inconsistent with the characterization of endogenous GRH in normal subjects (29) and in patients with GRH-secreting tumors $(14,26)$ in which the predominant form of GRH has been reported to be unmodified GRH(1-44)- $\mathrm{NH}_{2}$ or GRH(1-40)-OH. The antibody used to characterize GRH in normal subjects was specific for the COOH-terminal region of GRH and should have been capable of detecting GRH(3-44)-NH $\mathrm{NH}_{2}$. However, it is unclear from the data presented whether the conditions used for HPLC would

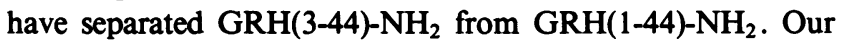
reports of endogenous tumor-derived GRH in plasma are more difficult to reconcile since the same separation conditions were used as in the present study. Among the possible explanations are: $(a)$ reduced or absent DAP activity in plasma of patients with GRH-secreting tumors, $(b)$ presence of other peptidases that metabolize GRH(3-44)- $\mathrm{NH}_{2}$ more rapidly than in normal subjects, and $(c)$ a difference in the molecular conformation of chemically synthesized GRH(1-44)- $\mathrm{NH}_{2}$ that renders it more susceptible to DAP cleavage than is the native hormone. Serum DAP-IV levels have been reported to be decreased in serum of patients with gastrointestinal and pancreatic tumors (30).

There are several physiological and clinical implications of the present results. In a previous report (31) large doses of $\mathrm{GRH}(1-40)-\mathrm{OH}$, administered as a single intravenous injection, were associated with a secondary increase in plasma GH levels 
at 2-3 $\mathrm{h}$. This was attributed to the persistence of a maximally stimulating concentration of GRH in circulation for the entire time period. This conclusion is no longer tenable, given the rapid half-time of GRH. Although a parallel in vivo study of GRH(140)-OH has not been performed, extrapolation of the in vitro data results in an estimated elimination $t_{1 / 2}$ of $10 \mathrm{~min}$. Thus, alternative explanations, relating to changes in the intracellular response to GRH or to changes in somatostatin secretion, appear more plausible. Other published data relating to plasma GRH levels after injection of exogenous GRH (32-34) are also likely to be incorrect, since the contribution of GRH metabolites to total measured GRH immunoreactivity is unknown. Finally, our results should be helpful in designing modifications of the GRH sequence that are resistant to enzymatic degradation in order to develop superactive analogs. Since enhanced growth in human GH deficiency can be achieved in some patients with continuous as well as intermittent GRH administration (35), the availability of more potent analogs will be of considerable clinical importance.

\section{Acknowledgment}

This work was supported in part by US Public Health Service grants AM-30067 and RR-0068.

\section{References}

1. Frohman, L. A., M. Szabo, M. Berelowitz, and M. E. Stachura. 1980. Partial purification and characterization of a peptide with growth hormone-releasing activity from extrapituitary tumors in patients with acromegaly. J. Clin. Invest. 65:43-54.

2. Rivier, J., J. Spiess, M. Thorner, and W. Vale. 1983. Characterization of a growth hormone releasing factor from a human pancreatic islet tumor. Nature (Lond.). 300:276-278.

3. Guillemin, R., P. Brazeau, P. Bohlen, F. Esch, N. Ling, and W. B. Wehrenberg. 1982. Growth hormone releasing factor from a human pancreatic tumor that caused acromegaly. Science (Wash. DC). 218: 585-587.

4. Ling, N., F. Esch, P. Bohlen, P. Brazeau, W. B. Wehrenberg, and R. Guillemin. 1984. Isolation, primary structure, and synthesis of human hypothalamic somatocrinin: growth hormone-releasing factor. Proc. Natl. Acad. Sci. USA. 81:4302-4306.

5. Gubler, U., J. J. Monahan, P. T. Lomedico, R. S. Bhatt, K. J. Collier, B. J. Hoffman, P. Bohlen, F. Esch, N. Ling, F. Zeytin, P. Brazeau, M. S. Poonian, and L. P. Gage. 1983. Cloning and sequence analysis of cDNA for the precursor of human growth hormone-releasing factor, somatocrinin. Proc. Natl. Acad. Sci. USA. 80:4311-4314.

6. Frohman, L. A., J. L. Thominet, C. B. Webb, M. L. Vance, H. Uderman, J. Rivier, W. Vale, and M. O. Thorner. 1984. Metabolic clearance and plasma disappearance rates of human pancreatic tumor growth hormone releasing factor in man. J. Clin. Invest. 73:1304-1311.

7. Gelato, M. C., O. Pescovitz, W. Nixon, R. D’Agata, F. Cassarola, D. L. Loriaux, and G. R. Merriam. 1984. Continuous intravenous infusions of growth hormone-releasing factor $1-44 \mathrm{NH}_{2}(\mathrm{GRF}-44)$ in normal men: pituitary responses and pharmacokinetics. Excerpta Med. Int. Congr. Ser. 652:605. (Abstr.)

8. Nicholson, W. E., G. S. DeCherney, R. V. Jackson, C. R. DeBold, H. Uderman, A. N. Alexander, J. Rivier, W. Vale, and D. N. Orth. 1983. Plasma distribution, disappearance half-time, metabolic clearance rate, and degradation of synthetic ovine corticotropin-releasing factor in man. J. Clin. Endocrinol. Metab. 57:1263-1269.

9. Sheppard, M., B. Shapiro, B. Pimstone, S. Kronheim, M. Berelowitz, and M. Gregory. 1979. Metabolic clearance and plasma half disappearance time of exogenous somatostatin in man. J. Clin. Endocrinol. Metab. 48:50-53.
10. Redding, T., A. Kastin, D. Gonzalez-Barcena, D. H. Coy, E. J. Coy, D. S. Schalch, and A. V. Schally. 1973. The half-life, metabolism and excretion of tritiated luteinizing hormone-releasing hormone (LHRH) in man. J. Clin. Endocrinol. Metab. 37:626-631.

11. Leppauluoto, J., P. Virkkunen, and H. Lybeck. 1972. Elimination of TRH in man. J. Clin. Endocrinol. Metab. 35:477-478.

12. Matsuyama, H., A. Ruhmann-Wennhold, L. R. Johnson, and D. H. Nelson. 1972. Disappearance rates of exogenous and endogenous ACTH from rat plasma measured by bioassay and radioimmunoassay. Metab. Clin. Exp. 21:30-35.

13. Schurmeyer, T. H., P. C. Avgerinos, P. W. Gold, W. T. Gallucci, T. P. Tomai, G. B. Cutler, Jr., D. L. Loriaux, and G. P. Chrousos. 1984. Human corticotropin-releasing factor in man: pharmacokinetic properties and dose-response of plasma adrenocorticotropin and cortisol secretion. J. Clin. Endocrinol. Metab. 59:1103-1108.

14. Frohman, L. A., and T. R. Downs. 1986. Measurement of growth hormone-releasing factor. Methods Enzymol. 124:371-389.

15. Stein, S., and L. Brink. 1982. Amino acid analysis of protein and peptides at the picomole level: the fluorescamine amino acid analyzer. Methods Enzymol. 79:20-25.

16. Pan, Y.-C., J. Wideman, R. Blacher, M. Chang, and S. Stein. 1984. Use of high-performance liquid chromatography for preparing samples for microsequencing. J. Chromatogr. 297:13-19.

17. Hawke, D., P. M. Yuan, and J. E. Shively. 1982. Microsequence analysis of peptides and proteins. Anal. Biochem. 120:302-311.

18. Merrifield, R. B. 1963. Solid phase peptide synthesis. I. The synthesis of a tetrapeptide. J. Am. Chem. Soc. 85:2149-2154.

19. Barany, G., and R. B. Merrifield. 1980. Solid-phase peptide synthesis. In The Peptides: Analysis, Synthesis, Biology. Vol. 2. E. Gross and J. Meienhofer, editors. Academic Press, New York. 1-284.

20. Wilfinger, W. W., W. J. Larsen, T. R. Downs, and D. L. Wilbur. 1984. An in vitro model for studies of intercellular communication in cultured rat anterior pituitary cells. Tissue \& Cell. 16:483-497.

21. Frohman, L. A., and L. L. Bernardis. 1968. Growth hormone and insulin levels in weanling rats with ventromedial hypothalamic lesions. Endocrinology. 82:1125-1132.

22. Genuth, S. D. 1972. Metabolic clearance of insulin in man. Diabetes. 21:1003-1012.

23. Lance, V. A., W. A. Murphy, J. Sueiras-Diaz, and D. H. Coy. 1984. Super-active analogs of growth hormone-releasing factor (1-29)amide. Biochem. Biophys. Res. Commun. 119:265-272.

24. Ling, N., A. Baird, W. B. Wehrenberg, N. Ueno, T. Munegumi, T. C. Chiang, M. Regno, and P. Brazeau. 1984. Synthesis and in vitro bioactivity of human growth hormone-releasing factor analogs substituted at position-1. Biochem. Biophys. Res. Commun. 122:304-310.

25. Coy, D. H., W. A. Murphy, J. Sueiras-Diaz, E. J. Coy, and V. A. Lance. 1985. Structure-activity studies on the N-terminal region of growth hormone releasing factor. J. Med. Chem. 28:181-185.

26. Frohman, L. A., and J.-O. Jansson. 1986. Growth hormonereleasing hormone. Endocr. Re. 7:223-253.

27. McDonald, J. K., and C. Schwabe. 1977. Intracellular exopeptidases. In Proteinases of Mammalian Cells and Tissues. A. J. Barrett, editor. Elsevier/North Holland Biomedical Press, Amsterdam. 311-391.

28. Rafferty, B., and D. Schulster. 1985. Radioimmunoassay for human growth hormone-releasing factor (hGRF 1-40): comparison of plasma immunoreactive GRF after intravenous and subcutaneous administration to rats. Mol. Cell. Endocr. 41:19-25.

29. Chihara, K., Y. Kashio, T. Kita, Y. Okimura, H. Kaji, H. Abe, and T. Fujita. 1986. L-dopa stimulates release of hypothalamic growth hormone-releasing hormone in humans. J. Clin. Endocrinol. Metab. 62: 466-473.

30. Hino, M., T. Nagatsu, S. Kakumu, S. Okuyama, Y. Yoshii, and I. Nagatsu. 1975. Glycyl-L-Prolyl $\beta$-Naphthylamidase activity in human. Clin. Chim. Acta. 62:5-11.

31. Vance, M. L., J. L. C. Borges, D. L. Kaiser, W. S. Evans, R. 
Furlanetto, J. L. Thominet, L. A. Frohman, A. D. Rogol, R. M. MacLeod, S. Bloom, J. Rivier, W. Vale, and M. O. Thorner. 1984. Human pancreatic tumor growth hormone releasing factor (hpGRF-40): dose response relationships in normal man. J. Clin. Endocrinol. Metab. 58: 838-844.

32. Evans, W. S., M. L. Vance, D. L. Kaiser, R. P. Sellers, J. L. C. Borges, T. R. Downs, L. A. Frohman, J. Rivier, W. Vale, and M. O. Thorner. 1985. Effects of intravenous, subcutaneous, and intranasal administration of human growth hormone releasing factor- 40 on serum growth hormone concentrations in normal men. J. Clin. Endocrinol. Metab. 61:846-850.

33. Losa, M., L. Bock, J. Schopohl, G. K. Stalla, O. A. Muller, and K. Von Werder. 1984. Growth hormone releasing factor infusion does not sustain elevated GH-levels in normal subjects. Acta Endocrinol. 107: 462-470.

34. Sassolas, G., S. Biot-Laporte, R. Cohen, A. E. Charf, S. Ferry, and $F$. Borson. 1985. Effects on growth hormone secretion following intravenous and subcutaneous injections of growth hormone-releasing factor (hGRF-44 $\mathrm{NH}_{2}$ ): comparison of immunoreactive plasma GRF levels. Clin. Endocrinol. 22:645-653.

35. Thorner, M. O., M. L. Vance, W. S. Evans, R. M. Blizzard, A. D. Rogol, K. Ho, D. A. Leong, J. L. C. Borges, M. J. Cronin, R. M. MacLeod, K. Kovacs, S. Asa, E. Horvath, L. A. Frohman, R. Furlanetto, G. Klingensmith, C. Brook, P. Smith, S. Reichlin, J. Rivier, and W. Vale. 1986. Physiological and clinical studies of GRF and GH. Recent Prog. Horm. Res. 42:589-632. 